\title{
You'll Love the Way it Makes You Feel \\ The Passion and Privation of Modern Work Culture
}

CAROLINE Hamilton

UNIVERSITY OF MELBOURNE

\author{
Melissa Gregg \\ Work's Intimacy \\ Polity, Cambridge, 2011 \\ ISBN $9780745650289(\mathrm{pb})$ \\ RRP $\$ 29.95$ \\ David Hesmondhalgh and Sarah Baker \\ Creative Labour: Media Work in Three Cultural Industries \\ Routledge, London, 2010 \\ ISBN $9780415677738(\mathrm{pb})$ \\ RRP \$44.95
}

'All work and no play makes Jack a dull boy,' goes the old proverb. The phrase is probably best known because of its appearance in the 1980 Stanley Kubrick film The Shining in which the main character (played by Jack Nicholson) spends months typing the phrase repeatedly onto an entire ream of paper while his family believe 
he is hard at work on his manuscript. The scene has always been something of a sick joke for freelance writers but as work hours stretch and work conditions become increasingly flexible for those in the knowledge economy Nicholson's descent into psychosis might be seen by some as a kind of cautionary tale.

There has been a noted turn to a doctrine of creativity in workplaces over the last few years and two recent books interrogate the significance of this increasingly common discourse by talking directly to those at the conceptual coalface. David Hesmondhalgh and Sarah Baker's Creative Labour: Media Work in Three Cultural Industries is a comprehensive study based on empirical research carried out in England during 2006 and 2007 in the fields of magazine publishing, television production and music recording. Melissa Gregg's Work's Intimacy undertakes a similar project, this time from the Australian perspective. Gregg's qualitative study moves between the offices and homes of workers to provide insight into the personal, family and wider social tensions emerging in today's diverse (and often dispersed) work environment. Although Gregg's study isn't focused exclusively on those working in the creative or cultural industries her research uncovers the preference for white collar workers to understand their roles as at least nominally creative, and in documenting the highs and lows of flexible, technology-enabled working lives she reveals the many creative solutions and justifications workers develop to deal with their often complicated work lives and work situations.

Gregg's study is motivated by the prevailing social discourse regarding workthat it constitutes the individual's sense of self worth and determination. Recently, a new set of work conditions and experiences have influenced this accepted logic. New media technologies from mobile phones to laptops with wireless internet connections all appeal to our desire for the freedom to work where we want, when we want, but the consequence of this shift is that work has moved outside the office and off the desktop into cafés, trains, kitchens and bedrooms. This is what Gregg refers to as 'presence bleed', with work impinging on the personal lives of employees in new and unforeseen ways.

In the first section of her book Gregg provides evidence of this social shift with reference to advertising, popular culture (including archetypal 'workplace' narratives such as The Office and Mad Men) and recent changes in government policy. With these examples she is able to demonstrate that much of the new 
technology to which we attribute the problems of over-connection or selfexploitation in the workplace simply diversify older models of work.

In the second half of the book Gregg's study turns to qualitative evidence for the normalisation of online, mobile work cultures. Here Gregg covers a broad range of issues, examining mobile working; part-time and contract working; the use of social networking; online branding; and the implications of working from home. Academic readers may see parallels with their own working lives in the case studies cited, a result of the twenty participants interviewed being professionals employed in large organisations in education, government, broadcasting and telecommunications. Gregg collated their responses throughout annual interviews over a three-year period.

The results reflect a mixed attitude to changes in working life in the last decade. For example, many employees enjoyed the freedoms of work-from-home arrangements and embraced technologies that allowed them to connect to work at different times and places. Yet, some of these same workers admit to increased pressures and tensions as a result of this convenience-attempts are made to conceal work being done at home from other family members, for instance, while others cite the need to demonstrate their work presence by rapid response to email even outside of office hours. Gregg's study reveals many participants taking personal responsibility for their expanded work roles, accepting that their choice to work outside scheduled hours, or away from traditional workplaces, involved shifting expectations about the nature of work. For most participants in Gregg's study the workplace was an unproductive, inefficient site not suited to the primary business of working. As Gregg explains, home is 'a consolatory space' (53) accommodating the limitations of modern workplaces.

An important outcome of Gregg's study was the documentation of the rise of Facebook and its changing position in the workplace. For Gregg, the social networking site's popularity among the 'mainstream, middle-class, office-dwelling user base best illustrates the seamless combination of professional and personal identity that is at stake in the shift to intimate work where "contact" equals "friend"'. (87) Gregg's analysis of the role of Facebook in cushioning the impact and demands of mobile work life offers a valuable contribution to study of the site and its evolution from a social to a commercial application. Gregg observes how the 
website, initially prohibited in many workplaces on the grounds of worker distraction, eventually became a central platform for many businesses keen to promote themselves as customer 'friendly' and highly 'like'-able. Gregg rightly notes how employers came to recognise the advantages of the application's 'coercive intimacy' in promoting brands and organisations. The consequences of 'Facebooking' for work, according to Gregg, is that 'users never quite know whether they are performing their endearing personality as an end in itself or for purposes of profit'. (96) In this context Gregg discusses the provocative idea of the 'labour of friendships'-that is, who will be admitted to the network; given access to the benefits of connection.

Gregg's study also provides an account of some users keen to use Facebook as a dividing line between their professional and personal identities; for these workers Facebook becomes a mark of genuine interaction, carefully protected from encroachments of the demands of work. The book offers useful evidence of the way in which social networks offer the intimate encounters that are otherwise lost amidst the demands of the increasingly networked working life. An important aspect to Gregg's thesis in the second half of her study is that the popularity of online social networks such as Facebook does not merely illustrate the dominance of a culture of commercialised public disclosure but, in the context of new working lifestyles, the popularity of Facebook as a site for intimate contact with friends and family is a response to the fact that the demands of work 'prevent the likelihood of more significant long term connections beyond the computer screen'. (90) On this point, Gregg poses an important question for both employers and employees alike: 'if social media are one of the key means by which employees resist the intrusion of work on their personal lives, what kind of labour politics will be needed to resist management pressures to pilfer friendship networks for business profit?' (105)

In recent cultural studies' discussions of labour rights, work culture and the question of 'quality of life' have been well developed but the issue of 'quality of work' requires more sustained investigation. In Creative Labour, Hesmondhalgh and Baker analyse the quality of workers' experiences in jobs in what they term the 'cultural industries' in the United Kingdom. This emphasis on quality of work, and in particular on what the pair term 'good' and 'bad' work make the book an especially compelling contribution to the field, with the authors directly addressing the current 
lack of political clarity about the better forms creative work might take. Like Gregg, Hesmondhalgh and Baker are concerned with giving voice to workers, asking: what kinds of experiences do these jobs offer their workers?

Effectively blending the theoretical and the empirical, Hesmondhalgh and Baker begin by providing a comprehensive survey and analysis of the formidable body of research on cultural production. The pair draw on Marxist theory, poststructuralism and liberal political thought, and from scholarship in the fields of media, communication, and cultural studies, the sociology of work, organisational, business and management studies, and social and political theory to shed light on the specifics of labour in cultural production. When it comes to this last point the authors identify three major paradigms of analysis (political economy of culture; organisational, business and management studies; and cultural studies) and note how (until recently) the labour involved in cultural production has been a neglected area of study, speculating on why this might have been the case and why 'creativity in work' is the object of the aspirations so often held about employment.

The book's second section turns to documenting and analysing the experiences of sixty research participants. Relying on interviews with employees and participant-observation of work in television, magazine journalism and music, the pair use their data to document a workaday world that sits somewhere between the accounts of those who celebrate creative jobs in the information-technology driven economy for their flexibility, autonomy and social engagement and those critics who view these same roles as exploitative, insecure and socially disruptive. An important advantage of Hesmondhalgh and Baker's book is that the pair have interviewed and observed creative workers across a number of cultural industries, whereas most previous studies have been confined to one particular cultural or related industry. Second, they have also focused on workers' reports of their subjective experience of the quality of their working lives, lending the study rich granular data. In this way, the book develops a detailed portrait of just what it is that makes this form of work socially relevant.

While the turn to creativity in business management (think Richard Florida) may be a little past its peak, its effects in public policy and private enterprise still continue to resonate. For many people nowadays the degree to which their job offers the chance for them to be creative is an important feature of its quality. 
Creative Labour analyses the tensions inherent in such expectations: between commerce and creativity, between alienation and autonomy, and between selfrealisation and self-exploitation.

In their final chapter, the authors return to questions of quality of work and labour ethics. They discuss the role of trade unions and of networks of creative workers but they also address questions of 'self-exploitation' and the relationship of good work to notions of a good life. Hesmondhalgh and Baker make the important observation, for instance, that self-exploitation is a misnomer (albeit a catchy one):

The seemingly individual decisions made by such workers are partly the result of structural forces shaping the values that people hold about how best to live their lives. But there remains a crucial difference between workers who are closely supervised and monitored and those educated professionals who internalise their commitment to hard work. Ultimately it has to be individuals who have to make ethical choices about the degree to which they commit themselves to hard work. (226)

The authors are also careful to acknowledge that despite the sometimes demoralising circumstances of creative workers their daily tasks hardly ever involve work that is dangerous, or would be classified by others as disgusting or humiliating.

The reality for those hard at work in the knowledge economy is that whether freelance, part-time, full-time or working from home, many people never stop being at work. Increasingly, this constancy is the way in which value is derived and expressed. Always working means always mattering. Seeking reassurance through obsessive networking is a habit more often associated with B-list celebrities or teenagers hooked into the social web via mobile phone but these two books both suggest it is a modern workplace hazard.

Caroline Hamilton is a McKenzie Fellow with the Publishing and Communications program at the University of Melbourne. She is presently working on a study of the work lives and culture of Australian small publishers and freelancers. She is also coediting an issue of Cultural Studies Review on the subject of 'Amateur Economies', which will be published in March 2013. 